\title{
Discrete quinolinic acid lesions of the lateral but not of the medial caudate-putamen reversed haloperidol-induced catalepsy in rats
}

\author{
W. Hauber ${ }^{1}$ and W. J. Schmidt ${ }^{2}$ \\ ${ }^{1}$ Department of Animal Physiology, Biological Institute, University of Stuttgart, and \\ ${ }^{2}$ Department of Neuropharmacology, Zoological Institute, University of Tübingen, \\ Tübingen, Federal Republic of Germany
}

Accepted June 22, 1993

\begin{abstract}
Summary. Discrete lesions in the medial or lateral subregion of the rostral caudate-putamen (CP) were induced by bilateral intracerebral injections of a low dose of quinolinic acid ( $30 \mathrm{nmol}$ in $1 \mu \mathrm{l} / \mathrm{per}$ side) in rats. Quinolinic acid lesions in the lateral CP potently reversed haloperidol-induced catalepsy $(0.5 \mathrm{mg} /$ $\mathrm{kg}$,i.p.), while lesions in the medial CP were not effective. Spontaneous locomotor activity was not altered significantly after quinolinic acid lesions of either the medial or lateral CP. These results show that the lateral CP seems to be important for the expression of neuroleptic-induced catalepsy and thus further corroborate the concept of a functional heterogenity of the striatum.
\end{abstract}

Keywords: Catalepsy, spontaneous locomotor activity, quinolinic acid, haloperidol, lateral caudate-putamen, medial caudate-putamen, rat:

\section{Introduction}

Systemic administration of dopamine (DA) D 1 or D 2 receptor-antagonists induce in rats catalepsy (Ögren and Fuxe, 1988), i.e. a state of postural immobility (akinesia) and muscular rigidity. The available evidence suggests that catalepsy mainly originates from a blockade of D 1 or D 2 receptors in the caudate-putamen (CP) or a decreased presynaptic DA activity in this structure, since intrastriatal infusions of DA-antagonists (Elliott et al., 1990 a; Ossowska et al., 1990), 6-hydroxydopamine-lesions of the mesostriatal DA system or reserpine treatment produced catalepsy (see Schmidt et al., 1992 for review).

The striatum receives not only DAergic projections from the mesencephalon, but also extensive and topographically arranged afferents from the cerebral cortex (Webster, 1961) using most probably glutamate as transmitter (Fonnum, 1984). These glutamatergic afferents play an important role for the expression of catalepsy, since lesions of the corticostriatal pathway reduced neuroleptic- 
induced catalepsy (Scatton et al., 1982; Warenycia et al., 1987; Worms et al., 1985). Furthermore, glutamate that derives from corticostriatal pathways and acts on the N-methyl-D-aspartate (NMDA) subtype of glutamate receptors is a prerequisite for the cataleptogenic action of haloperidol, because infusion of the competitive NMDA-antagonist D-2-amino-5-phosphonopentanoic acid (AP-5) into the CP or frontal decortication reduced neuroleptic-induced catalepsy (Yoshida et al., 1991). In addition, striatal infusion of NMDA restored haloperidol-induced catalepsy in frontally decorticated rats in this study.

It is likely that striatal output neurons bearing NMDA receptors mediate these anticataleptic effects, since striatal lesions with quinolinic acid (Schmidt and Bischoff, 1988; Calderon et al., 1988) potently antagonized neurolepticinduced catalepsy. Quinolinic acid is a selective agonist at the NMDA receptor and a potent neuroexcitotoxin which preferentially destroys spiny neurons using GABA and substance $P$ or enkephalin as transmitter while sparing striatal afferents and interneurons (Beal et al., 1988).

However, little is known in which subregion of the CP this effect was brought about. There is considerable anatomical, biochemical and behavioural evidence for a functional differentiation of the striatum (see Goldman-Rakic and Selemon, 1990 for review). Various studies showed that the more rostral part of the striatum is the subregion most sensitive to the cataleptogenic effects of neuroleptics (Ellenbroek et al., 1985; Klockgether et al., 1988; Ossowska et al., 1990). This view was further confirmed by the finding that infusion of the competitive NMDA-antagonist AP-5 into the rostral part, but not into the intermediate part of the CP abolished neuroleptic-induced catalepsy (Yoshida et al., 1991). On the other hand there is growing evidence that not only the anterio-posterior, but also the medio-lateral organization of the striatum is behaviourally relevant. Lesions in the medial part of the CP produced selective impairments in maze performance and discrimination learning (Wikmark et al., 1973; Divac et al., 1978; Pisa and Cyr, 1990; Hauber and Schmidt, 1989) whereas lesions in the lateral part of the CP induced motor deficits in various tasks (Sabol et al., 1985; Pisa, 1988; Pisa and Schranz, 1988; Pisa and Cyr, 1990). The medial and lateral subregion of the CP mediate behavioural functions which are related to those mediated by the anatomically linked regions of the cortex. Thus it was proposed that there may exist different cortico-striatal functional loops which may mediate different aspects of behaviour (Alexander et al., 1986). In the rat, the medial subregion of the $\mathrm{CP}$ receives prominent glutamatergic projections from the medial prefrontal cortex. This cortico-striatal loop has been implicated in processing cognitive, i.e. non-motor, complex functions. In contrast, the lateral subregion of the $\mathrm{CP}$ and the anatomically related sensorimotor cortical regions have been suggested to mediate motor functions (see Robbins and Brown, 1990 for review).

In the present study, we tested this hypothesis with regard to neurolepticinduced catalepsy. We investigated the effects of lesions in the motor loop or cognitive loop on neuroleptic-induced catalepsy using quinolinic acid infusions 
in the respective subregions of the rostral CP. It has been already shown that quinolinic acid lesions counteract neuroleptic-induced catalepsy (see above). However, in these studies high doses of quinolinic acid were used and the resulting massive striatal damage thus prevented to detect the striatal subregion which may be relevant to this effect. Therefore, a low dose of quinolinic acid was used in this study to produce relatively circumscribed lesions. It was expected that the expression of catalepsy which is a motor phenomenon depends of the integrity of the motor loop. Thus discrete lesions in the relevant motor subregion in the CP should counteract neuroleptic-induced catalepsy, while lesions in the cognitive loop should not alter this response. We used lesion placements in the medial and lateral subregion of the rostral $\mathrm{CP}$ which are not exactly in the same anterio-posterior plane. According to anatomical studies the medial prefrontal cortex projects primarily to the most rostral parts of the medial $\mathrm{CP}$, while the sensorimotor cortex mainly projects to a more caudal subregion of the lateral CP (Berendse et al., 1992; McGeorge and Faull, 1989). Thus the placement for the medial lesion was more rostral than for the lateral lesion.

We report here that quinolinic acid lesions in the lateral $\mathrm{CP}$, but not in the medial CP potently reversed haloperidol-induced catalepsy, while spontaneous motor activity measured in an open field was not altered significantly after lesions in these striatal subregions.

\section{Materials and methods}

Animals

Twenty-five male Sprague-Dawley rats (Interfauna, Tuttlingen, F.R.G.) weighing 220 $250 \mathrm{~g}$ were used. They were housed in groups (5 per cage) and provided with $12 \mathrm{~g}$ standard laboratory chow per rat/day. Water was freely available. The animals were kept on a 12$\mathrm{h}$ light-dark cycle (light 06.00-18.00). The temperature in the colony room was adjusted on $22 \pm 3{ }^{\circ} \mathrm{C}$. Prior to this study, the animals were trained in a reaction time experiment (Hauber et al., 1991). No drugs were administered during this test.

\section{Surgery}

Surgery was performed under sodium pentobarbital (Serva, Heidelberg, F.R.G.) anaesthesia $(50 \mathrm{mg} / \mathrm{kg}$, i.p.) combined with atropine sulfate (Serva, Heidelberg, F.R.G.) pretreatment $(0.25 \mathrm{mg} / \mathrm{kg}$, i.p.). Rats were placed in a Trent Wells stereotaxic instrument and quinolinic acid (Sigma, Deisenhofen, F.R.G.)(30 nmol in $1 \mu 10.1 \mathrm{M}$ phosphate buffer, pH 7.0) or vehicle $(1 \mu 10.1 \mathrm{M}$ phosphate buffer, $\mathrm{pH} 7.0$ ) was infused via a 26 gauge cannula at a constant rate over $10 \mathrm{~min}$. The cannula was left in place for $2 \mathrm{~min}$ after the infusion. Lesions in the medial or lateral subregion of the $\mathrm{CP}$ were made at the following placements according to the atlas of Paxinos and Watson (1986): medial: AP: + 2.0, L 2.0, V 5.0; lateral: AP + 0.9, L 3.5, V 5.5.

\section{Histology}

At the end of the behavioural testing the animals were anaesthetized with sodium pentobarbital $(50 \mathrm{mg} / \mathrm{kg}$, i.p.) and transcardially perfused with $0.9 \%$ saline followed by a $4 \%$ solution of phosphate buffered formalin ( $\mathrm{pH}$ 7.4). Brains were removed, postfixed and thereafter stored in $30 \%$ sucrose solution. Coronal sections of $40 \mu \mathrm{m}$ were cut in a cryostat 
(Reichert \& Jung, F.R.G.) and stained with cresyl violet. The sections were examined by light microscopy for qualitative assessment of quinolinic acid-induced neuronal damage. The areas of neuronal loss and gliosis from different anterio-posterior planes revealed by cresyl violet staining were mapped on standardized brain sections from the atlas of Paxinos and Watson (1986).

\section{Procedure}

Two weeks after the lesion spontaneous locomotor activity of the animals was assessed in an open field $(69 \times 69 \mathrm{~cm})$ divided by lines in 9 squares of equal size. The open field box was opaque and illuminated by 4 red light bulbs $(20 \mathrm{~W})$; back ground noise was masked by a fan. Each animal was placed individually for $10 \mathrm{~min}$ into the open field. Locomotor activity was monitored by video recording and evaluated by counting the number of line crossings during the observation period. The following day, the animals were tested for catalepsy induced by intraperitoneal injection of $0.5 \mathrm{mg} / \mathrm{kg}$ haloperidol (Janssen, Neuss, F.R.G.). Thirty and $60 \mathrm{~min}$ after injection of haloperidol the degree of catalepsy was assessed in 3 tests performed in the following order (Scheel-Krüger, 1983): 1.) Bar: both forelegs were placed on a horizontal bar ( $9 \mathrm{~cm}$ above the surface). 2.) Podium: one forleg was placed on a podium ( $3 \mathrm{~cm}$ high). 3.) Grid: an animal was clinged to a vertical wire grid. The latency from paw placement until complete removal of one paw from a support was measured (maximum 180s) and termed here as descent latency.

\section{Statistics}

The data are presented as mean descent latencies and standard errors of the mean (SEM) for each test and group with infusions in either the medial $\mathrm{CP}$ (quinolonic acid, $\mathrm{n}=7$; vehicle, $\mathrm{n}=5$ ) or lateral $\mathrm{CP}$ (quinolinic acid, $\mathrm{n}=7$; vehicle, $\mathrm{n}=6$ ). The data were subjected to a two-tailed Mann-Whitney U-test. Differences were considered to be significant if the p-value was less than 0.05 .

\section{Results}

\section{Spontaneous locomotor activity}

The spontaneous locomotor activity of animals with quinolinic acid lesions of the medial CP was not significantly different from their controls $(U=15$, $\mathrm{p}>0.05$ ). No significant differences were also found between animals with quinolinic acid lesions in the lateral $\mathrm{CP}$ and their controls $(\mathrm{U}=12, \mathrm{p}>0.05)$, but the locomotor activity of laterally lesioned rats was enhanced (Fig. 1).

\section{Catalepsy}

Quinolinate lesions of the medial CP induced a marginal reduction of the degree of catalepsy, since descent latencies were shorter than those of control animals in each test (Fig. 2). These differences were not significant [grid: U (30 min) $=8.5, \mathrm{p}>0.05, \mathrm{U}(60 \mathrm{~min})=12, \mathrm{p}>0.05 ;$ podium: $\mathrm{U}(30 \mathrm{~min})=9, \mathrm{U}$ $(60 \min )=14, p>0.05$; bar: $U(30 \mathrm{~min})=12.5, p>0.05, U(60 \mathrm{~min})=17$, $\mathrm{p}>0.05]$.

By contrast, lesions of the lateral $\mathrm{CP}$ induced a significant reduction of the descent latencies in each test [grid: $\mathrm{U}(30 \mathrm{~min})=1, \mathrm{p} \leqslant 0.002, \mathrm{U}(60 \mathrm{~min})=2$, 


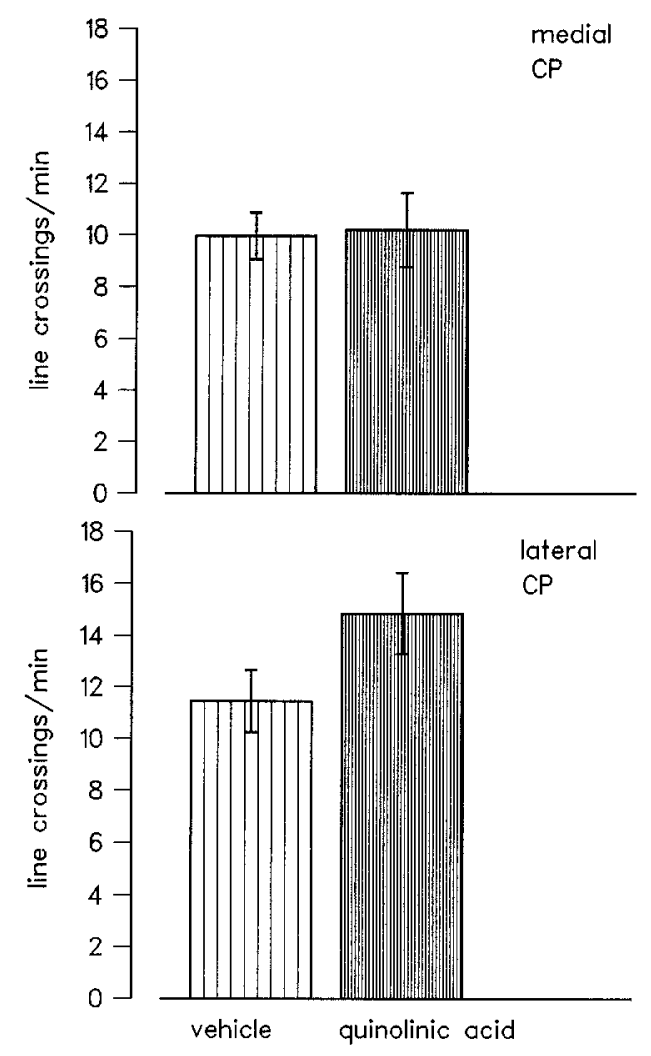

Fig. 1. Spontaneous locomotor activity in an open field of animals with quinolinic acid lesions $(n=7)$ or vehicle infusions $(n=5)$ in the medial caudate-putamen $(C P)$ and quinolinic acid lesions $(n=7)$ or vehicle infusions $(n=6)$ in the lateral caudate-putamen. Mean line crossings $( \pm$ SEM) were not significantly different $(p>0.05$; Mann-Whitney U-test, two-tailed)

$\mathrm{p} \leqslant 0.004$; podium: $\mathrm{U}(30 \mathrm{~min})=5, \mathrm{p} \leqslant 0.022, \mathrm{U}(60 \mathrm{~min})=6, \mathrm{p} \leqslant 0.034$; bar: $\mathrm{U}(30 \mathrm{~min})=6, \mathrm{p} \leqslant 0.034, \mathrm{U}(60 \mathrm{~min})=0.002]$ (Fig. 3).

\section{Histology}

Figure 4 shows the extent of the quinolinic acid-induced neuronal cell loss and gliosis in medial or lateral striatal areas. Quinolinic acid infusion produced a circumscribed area of neuronal cell loss (Fig. 5). Within this area a moderate degree of gliosis was found. Ventricular alterations or striatal shrinkage were not observed. The size of the lesions was relatively homogeneous within each group of lesioned animals. In addition, the overlap between the extent of lesions in the medial and lateral CP was minimal. In control animals no signs of neurodegeneration were detected except gliosis along the cannula tack and at the cannula tip (not shown). 

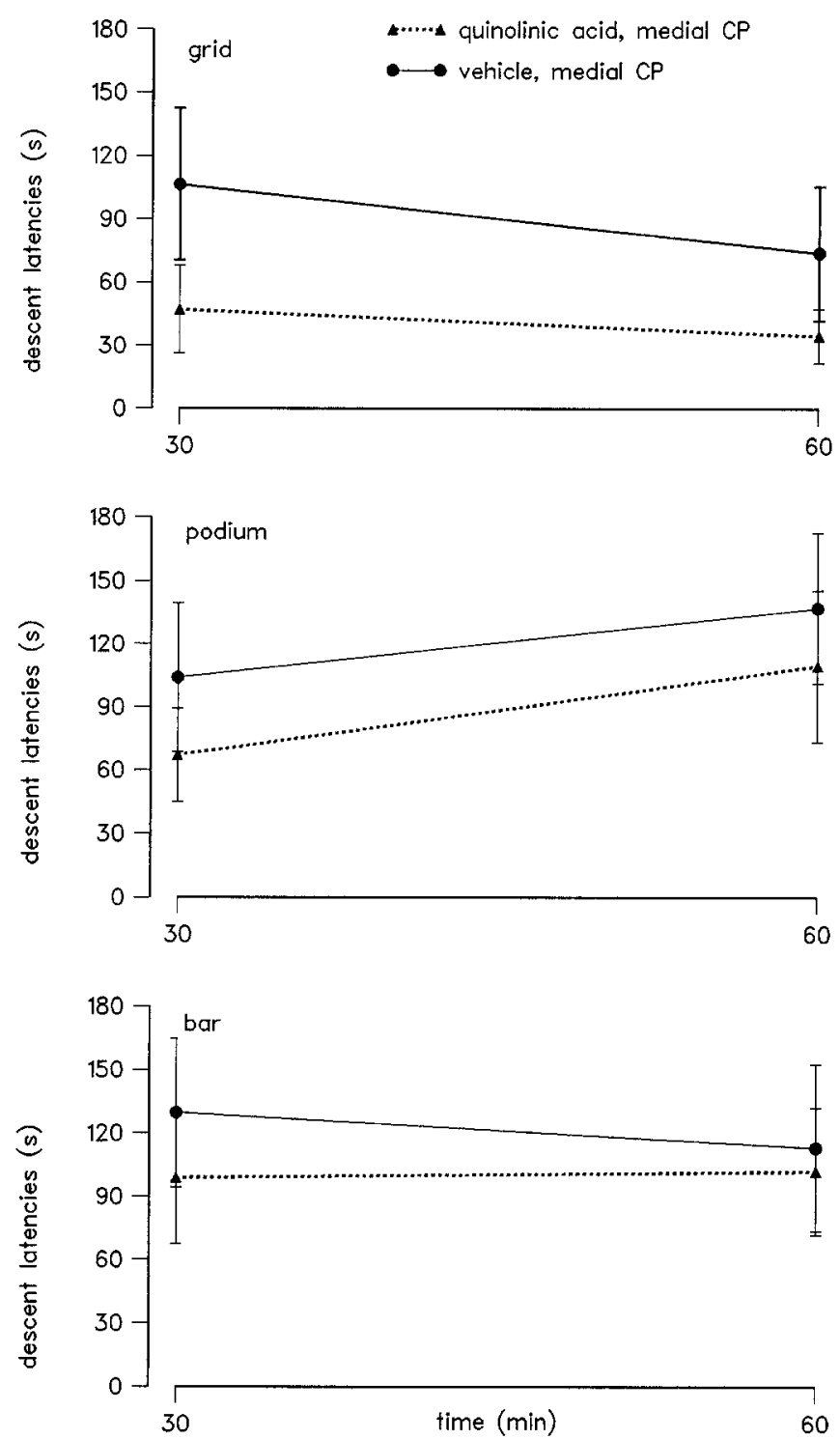

Fig. 2. Descent latencies $( \pm$ SEM) of animals with quinolinic acid lesions $(n=7)$ or vehicle infusions $(\mathrm{n}=5)$ in the medial caudate-putamen $(\mathrm{CP})$ tested for haloperidol $(0.5 \mathrm{mg} / \mathrm{kg}$, i.p.)-induced catalepsy. Descent latencies were not significantly different ( $p>0.05$; MannWhitney U-test, two-tailed)

\section{Discussion}

The histological examination of the striatal tissue revealed that a low dose of quinolinic acid, a potent neuroexcitotoxin and a selective agonist at the NMDA subtype of glutamate receptors, produced consistenly a circumscribed neuronal loss and a reactive gliosis without ventricular alterations. This result confirms previous findings showing that even low doses of quinolinate produced a prominent neuronal degeneration (Churchill et al., 1990; Davies and Roberts, 1988) 

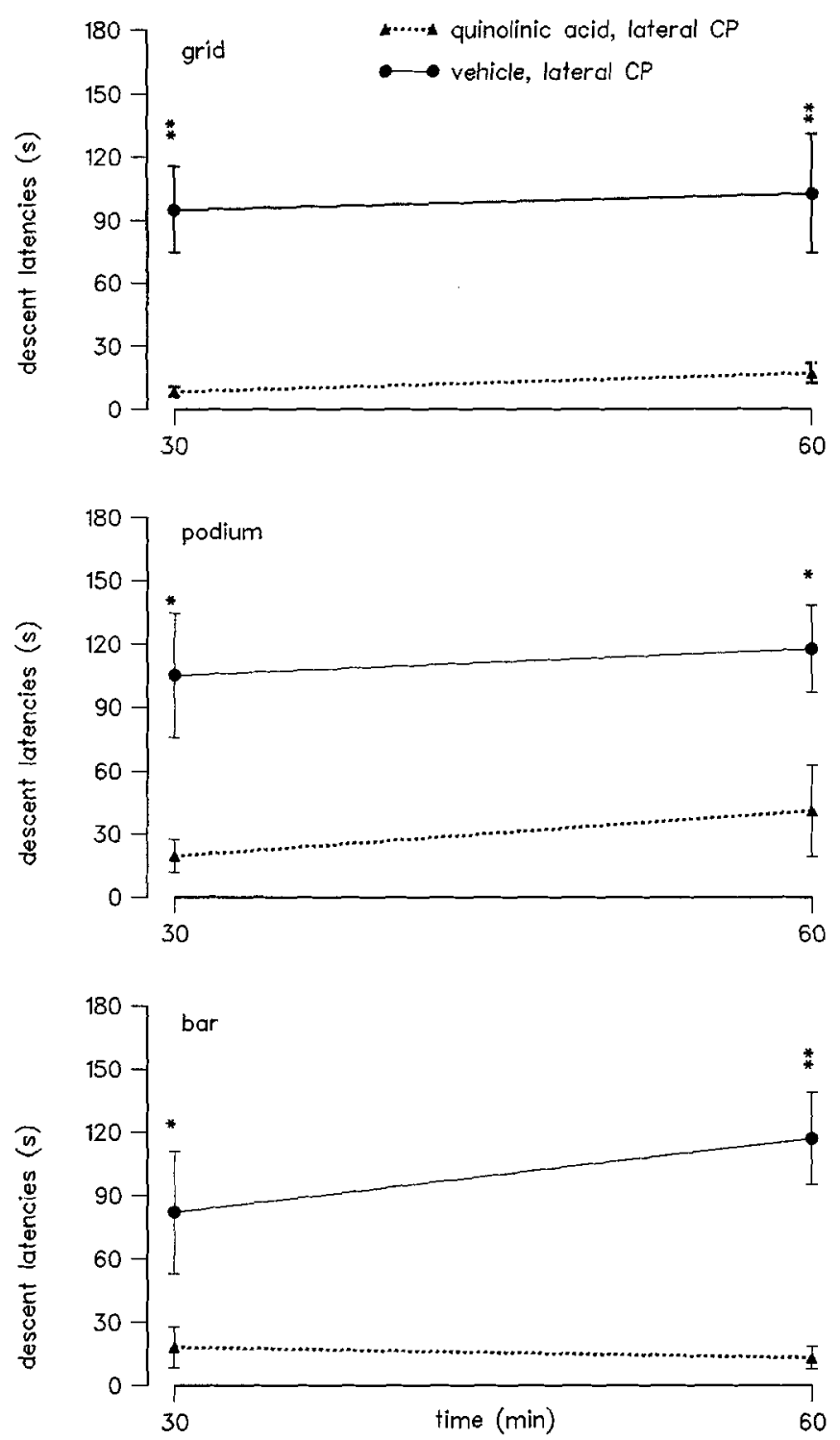

Fig. 3. Descent latencies ( \pm SEM) of animals with quinolinic acid lesions $(n=7)$ or vehicle infusions $(n=6)$ in the lateral caudate-putamen $(C P)$ tested for haloperidol $(0.5 \mathrm{mg} / \mathrm{kg}$,i.p.)induced catalepsy. ${ }^{*} \mathrm{p}<0.05 ;{ }^{* *} \mathrm{p}<0.005$; Mann-Whitney U-test, two-tailed

and that the threshold dose of quinolinate producing striatal lesions of a consistent size is about 30 nmol (Davies and Roberts, 1988). Numerous studies have shown that striatal quinolinic acid injections induced a pronounced degeneration of spiny neurons containing GABA and substance P/enkephalin, whilst aspiny neurons were preserved (see Beal, 1992 for review). In addition, cholinergic neurons were spared at least at the dose used here (Davies and Roberts, 1988). Thus quinolinic acid-induced behavioural effects observed in the present study are most probably due to the loss of striatal GABAergic projection neurons bearing NMDA receptors. 

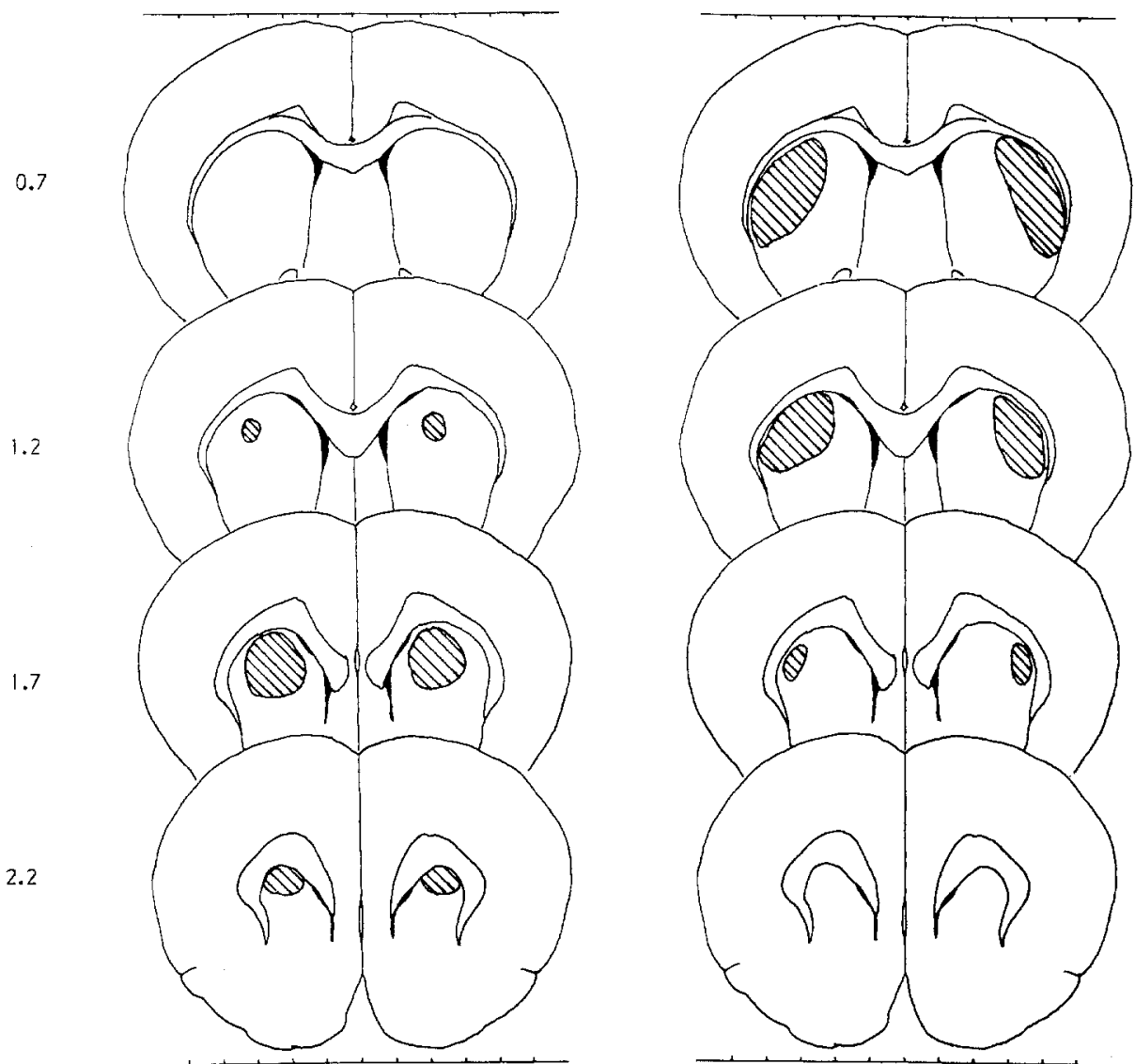

Fig. 4. Coronal sections showing the location and extent of the lateral (right) and medial (left) quinolinic acid lesions of the caudate-putamen, defined by areas of neuronal loss ( $\mathrm{n}=7$, respectively). Numbers represent the anterio-posterior plane; scaling of the abscissae in mm (based on the atlas of Paxinos and Watson, 1986)

The present study revealed that relatively small lesions of either the medial or lateral $\mathrm{CP}$ did not significantly affect spontaneous locomotor activity. This is accordance with a report of Sanberg et al. (1989) demonstrating that extensive lesions with quinolinic acid doses of $150-225 \mathrm{nmol}$ are required to produce locomotor abnormalities (but see Emerich et al., 1991).

Furthermore, we found that lateral striatal lesions induced a massive anticataleptic effect while medial lesions were not effective. At variance with these results are data from Calderon et al. (1988) showing that only striatal infusion of high doses (150-225 nmol) quinolinate dose-dependently abolished haloperidol-induced catalepsy while a lower dose $(75 \mathrm{nmol})$ induced no overall significant decrease in the catalepsy response. Several reasons may contribute to these discrepancies: First, in the study of Calderon et al. (1988) a different lesion placement (coordinates with reference to bregma: $\mathrm{AP}+1.3 \mathrm{~mm} ; \mathrm{ML} \pm 2.5 \mathrm{~mm}$, DV $5.2 \mathrm{~mm}$ from dura) and twice the dose of haloperidol was used, thus more extensive lesions were probably necessary to reduce the catalepic response. 


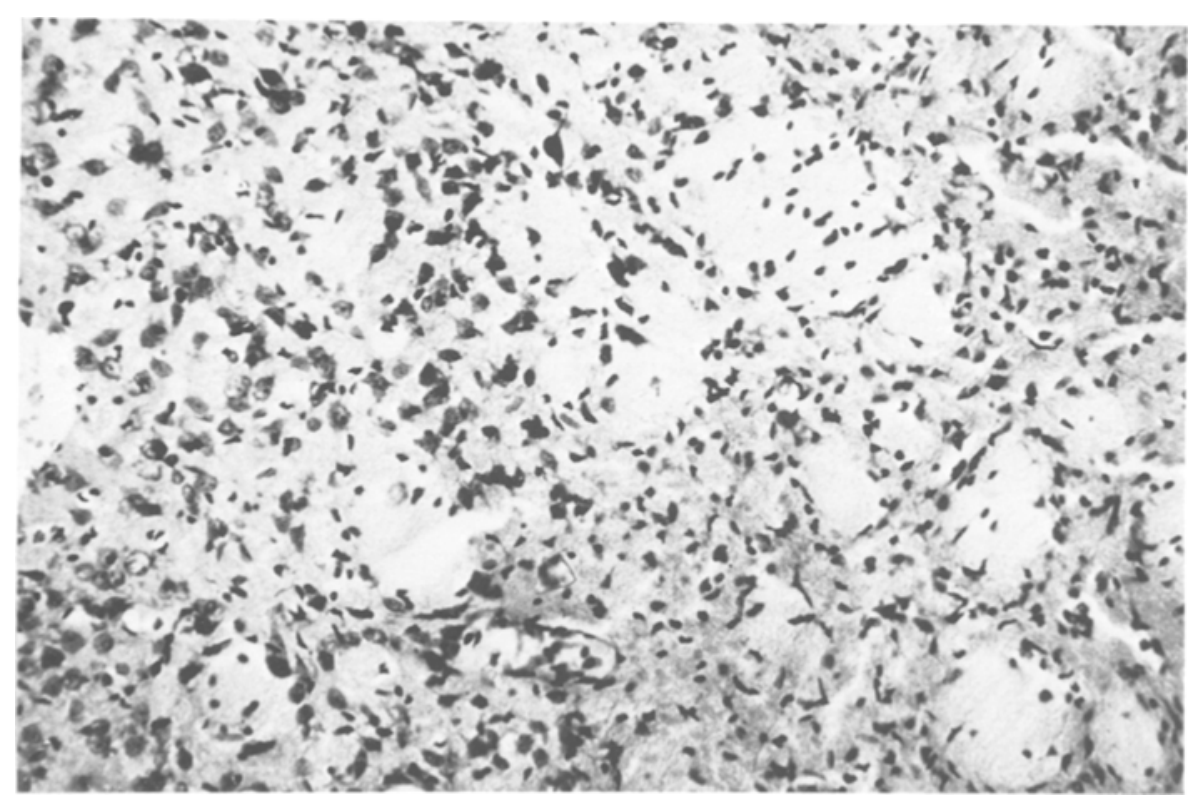

Fig. 5. Photomicrograph showing the borderline of intact and damaged striatal tissue after quinolinic acid lesion $(30 \mathrm{nmol})$ in the rat striatum. In intact tissue (left) numerous cresyl stained neurons can be seen which are absent in lesioned tissue (right). Magnification $128 \times$

Second, intrastriatal quinolinic acid injection in doses of about $200 \mathrm{nmol}$ induced ventricular enlargement, striatal atrophy (e.g. Emerich et al., 1991) and cerebral oedema in parts of the overlying cortical tissue as recently detected by in-vivo magnetic resonance imaging in rats (Sauer et al., 1992) which may interfere with the catalepsy response.

Thus the degree of the anti-cataleptic effect is not only dependent on the dose of quinolinic acid as shown by Calderon et al. (1988), but is also critically dependent on the striatal area of the quinolinic acid lesion as shown by the present study. The latter finding is in accordance with the view of a functional heterogenity of the striatum. In the rat, the medial part of the $\mathrm{CP}$ receives prominent glutamatergic projections from the prefrontal cortex and this corticostriatal loop has been implicated in processing cognitive functions. In contrast, the lateral striatum and the anatomically related sensorimotor cortical regions have been suggested to mediate motor functions (see Introduction). The present results further corroborate this concept since we found a functional differentiation of the medial and lateral $\mathrm{CP}$ with regard to catalepsy: the lateral $\mathrm{CP}$ as a part of the motor loop is a prerequisite for the expression of haloperidol induced catalepsy. Striatal infusion of haloperidol induced hindlimb rigidity in rats (Ellenbroek et al., 1988) as detected by a paw test (Ellenbroek et al., 1987). This effect could be mediated by haloperidols action within the lateral CP which includes limb representations in rats (Ebrahimi et al., 1992). Thus a lesion in the lateral CP may counteract hindlimb rigidity and contribute to the anticataleptic effect observed in the present study. 
The concept of functional cortico-striato-cortical loops further implicates that lesions in different parts of the same loop should have similar behavioural consequences. This was in fact confirmed in different paradigms. For instance, lesions within the medial prefrontal cortex or the medial striatum produced similiar impairments in maze learing (Dunnett and Iversen, 1981; Simon and LeMoal, 1984; Wikmark et al., 1973). The avaible catalepsy data further support a role of the motor loop for the expression of catalepsy: while extensive lesions of the frontal cortex reversed neuroleptic-induced catalepsy (Scatton et al., 1982; Warenycia et al., 1987; Worms et al., 1985; Yoshida et al., 1991), lesions of the medial prefrontal cortex induced only a weak anti-cataleptic effect (Carter and Pycock, 1987).

Furthermore, the present results may have implications for the striatal site of action of systemically administered NMDA-antagonists: dizocilpine, a potent NMDA-antagonist reversed neuroleptic-induced catalepsy (Schmidt and Bubser, 1989; Metha and Ticku, 1990; Elliott et al., 1990b) and NMDA given systemically in combination with haloperidol potentiated the cataleptogenic effects of haloperidol (Metha and Ticku, 1990). From the present results one may conclude that within the CP the anti-cataleptic effects of systemically administered NMDA antagonists is mediated mainly through quinolinic acidsensitive projection neurons in the lateral $\mathrm{CP}$.

\section{Acknowledgements}

We are grateful to S. Schmidt and E. Wacker for excellent technical assistance. This research was supported by the Deutsche Forschungsgemeinschaft (SFB 307/A4).

\section{References}

Alexander GE, DeLong MR, Strick PL (1986) Parallel organization of functionally segregated circuits linking basal ganglia and cortex. Ann Rev Neurosci 9: 357-381

Beal MF (1992) Does impairment of energy metabolism result in excitotoxic neuronal death in neurodegenerative illness? Ann Neurol 31: 119-130

Beal MF, Kowall MW, Ellison DW, Mazurek MF, Swartz KJ, Martin JB (1986) Replication of the neurochemical characteristics of Huntington's disease by quinolinic acid. Nature 321: 168-171

Berendse HW, Galis-de Graaf Y, Groenewegen HJ (1992) Topographical organization and relationship with ventral striatal compartments of prefrontal corticostriatal projections in the rat. J Comp Neurol 316: 314-347

Calderon SF, Sanberg PR, Norman AB (1988) Quinolinic acid lesions of rat striatum abolish $\mathrm{D}_{1}$-and $\mathrm{D}_{2}$-dopamine receptor-mediated catalepsy. Brain Res 450: 403-407

Carter CJ, Pycock CJ (1978) Studies on the role of catecholamines in the frontal cortex. Br J Pharmacol 62: 402P

Churchill L, Dilts RP, Kalivas PW (1990) Changes in gamma-aminobutyric acid, $\mu$-opioid and neurotensin receptors in the accumbens-pallidal projection after discrete quinolinic acid lesions in the nucleus accumbens. Brain Res 511: 41--54

Davies SW, Roberts PJ (1988) Sparing of cholinergic neurons following quinolinic acid lesions of the rat striatum. Neuroscience 26: 387-393

Divac I, Markowitsch HJ, Pritzel M (1978) Behaviourial and anatomical consequences of small intrastriatal injections of kainic acid in the rat. Brain Res 151: 523-532 
Dunnett SB, Iversen SD (1981) Learning impairments following selective kainic acidinduced lesions in the neostriatum of rats. Behav Brain Res 2: 189-209

Ebrahimi A, Pochet R, Roger M (1992) Topographical organization of projections from physiologically identified areas of the motor cortex to the striatum in the rat. Neurosci Res 14: 39-60

Ellenbroek B, Schwarz M, Sontag KH, Jaspers R, Cools A (1985) Muscular rigidity and delineation of a dopamine-specific neostriatal subregion: tonic EMG activity in rats. Brain Res 345: 132

Ellenbroek BA, Peeters BW, Honig WM, Cools AR (1987) The paw test: a behavioural paradigm for differentiating between classical and atypical neuroleptic drugs. Psychopharmacology 93: 343-348

Ellenbroek BA, Van Den Hoven J, Cools AR (1988) The nucleus accumbens and forelimb muscular rigidity in rats. Exp Brain Res 72: 299-304

Elliott PJ, Close SP, Walsh DM, Hayes AG, Marriott AS (1990a) Neuroleptic- induced catalepsy as a model of Parkinson's disease. I. Effect of glutamate antagonists. J Neural Transm 2 [PD-Sect]: 79-89

Elliott PJ, Close SP, Walsh DM, Hayes AG, Marriott AS (1990 b) Neuroleptic-induced catalepsy as a model of Parkinson's disease. II. Effect of glutamate antagonists. J Neural Transm 2 [PD Sect]: 91-100

Emerich DF, Zubricki EM, Shipley MT, Norman AB, Sanberg PR (1991) Female rats are more sensitive to locomotor alterations following quinolinic acid-induced striatal lesions: effects of striatal transplants. Exp Neurol 111: 369-378

Fonnum F (1984) Glutamate: a neurotransmitter in the mammalian brain. J Neurochem 42: $1-11$

Goldman-Rakic PS, Selemon LD (1990) New frontiers in basal ganglia research. Trends Neurosci 13: 241-243

Hauber W, Schmidt WJ (1989) Effects of intrastriatal blockade of glutamateric transmission on the acquisition of T-maze and radial maze tasks. J Neural Transm 78: 29-41

Hauber W, Bubser M, Schmidt WJ (1991) Cortico-striatal functional loops and reaction time performance in rat. Eur $\mathbf{J}$ Neurosci 4:167

Klockgether T, Schwarz M, Turski L, Sontag KH (1988) Catalepsy after microinjection of haloperidol into rat medial prefrontal cortex. Exp Brain Res 70: 445

McGeorge AJ, Faull RLM (1989) The organization of the projection from the cerebral cortex to the striatum in the rat. Neuroscience 29: 503-537

Metha AK, Ticku MK (1990) Role of N-methyl-D-aspartate (NMDA) receptors in experimental catalepsy in rats. Life Sci $46: 37-42$

Ögren SO, Fuxe $\mathrm{K}$ (1988) $\mathrm{D}_{1}$ - and $\mathrm{D}_{2}$-receptor antagonists induce catalepsy via different efferent striatal pathways. Neurosci Lett 85: 333-338

Ossowska K, Karcz M, Wardas J, Wolfarth S (1990) Striatal and nucleus accumbens D1/ D2 dopamine receptors in neuroleptic catalepsy. Eur J Pharmacol 182: 327

Paxinos G, Watson C (1986) The rat brain in stereotaxic coordinates. Academic Press, Sydney

Pisa M (1988) Motor somatotopy in the striatum of rat: manipulation, biting and gait. Behav Brain Res 27: 21-35

Pisa M, Schranz JA (1988) Dissociable motor roles of the rat's striatum conform to a somatotopic model. Behav Neurosci 102: 429-440

Pisa M, Cyr J (1990) Regionally selective roles of rat's striatum in modality-specific discrimination learning and forelimb reaching. Behav Brain Res 37: 281-292

Robbins TW, Brown VJ (1990) The role of the striatum in the mental chronometry of action: a theoretical review. Rev Neurosci 2: $181-213$

Sabol KE, Neill DB, Wages SA, Church WH, Justice JB (1985) Dopamine depletion in a 
striatal subregion disrupts performance of a skilled motor task in the rat. Brain Res 335: $33-43$

Sanberg PR, Calderon SF, Giordano M, Tew JM, Norman AB (1989) The quinolinic acid model of Huntington's disease: locomotor abnormalities. Exp Neurol 105: 45-50

Sauer D, Allegrini PR, Thedinga KH, Massieu L, Amacker H, Fagg GE (1992) Evaluation of quinolinic acid induced excitotoxic neurodegeneration in rat striatum by quantitative magnetic resonance imaging in vivo. J Neurosci Methods 42: 69-74

Scatton B, Worms P, Lloyd KG, Bartholini G (1982) Cortical modulation of striatal functions. Brain Res 232: 331

Scheel-Krüger J (1983) The GABA receptor and animal behavior. In: Enna SJ (ed) The GABA receptors. Humana Press, Clifton NJ, pp 215-256

Schmidt WJ, Bischoff C (1988) Dopaminergic behavioural respones modulated by NMDA receptor antagonists. Psychopharmacology 96: 196

Schmidt WJ, Bubser M (1989) Anticataleptic effects of the N-methyl-D-aspartate antagonist MK-801 in rats. Pharmacol Biochem Behav 32: 1-3

Schmidt WJ, Bubser M, Hauber W (1992) Behavioural pharmacology of glutamate in the basal ganglia. J Neural Transm 38: 65-89

Simon H, Le Moal M (1984) Mesencephalic dopaminergic neurons: functional role. In: Catecholamines: neuropharmacology and central nervous system. Theoretical aspects. A R Liss, New York, pp 293-307

Warenycia MW, McKenzie GM, Murphy M, Szerb JC (1987) The effects of cortical ablation on multiple unit activity in the striatum following dexamphetamine. Neuropharmacology 26: 1107

Webster KE (1961) Cortico-striate interrelations in the albino rat. J Anat 95: 532-544

Wikmark RGE, Divac I, Weiss R (1973) Retention of spatial delayed alternation in rats with lesions in the frontal lobes. Brain Behav Evol 8: 329-339

Worms P, Willigens MT, Continsouza-Blanc D, Lloyd KG (1985) The effect of different types of cortical lesions on drug-induced catalepsy in rats: a pharmacological analysis. Eur J Pharmacol 113: 53

Yoshida Y, Ono T, Kizu A, Fukushima R, Miyagishi T (1991) Striatal N-methyl-Daspartate receptors in haloperidol-induced catalepsy. Eur J Pharmacol 203: 173-180

Authors' address: Dr. W. Hauber, Department of Animal Physiology, Biological Institute, University of Stuttgart, Pfaffenwaldring 57, D-70550 Stuttgart, Federal Republic of Germany

Received March 2, 1993 